\title{
Optimization of Acetylene Black Conductive Additive and Polyvinylidene Difluoride Composition for High Power Rechargeable Lithium-Ion Cells
}

G. Liu ${ }^{\mathrm{a}, \mathrm{z}}$, H. Zheng ${ }^{\mathrm{a}, \mathrm{c}}$, V. S. Battaglia ${ }^{\mathrm{a}}$, A. S. Simens ${ }^{\mathrm{b}, \mathrm{d}}$, A. M. Minor ${ }^{\mathrm{b}}$, and X. Song ${ }^{\mathrm{a}}$

${ }^{a}$ Environmental Energy Technologies Division, Lawrence Berkeley National Laboratory, Berkeley, CA 94720, USA

${ }^{\mathrm{b}}$ National Center for Electron Microscopy, Material Science Division, Lawrence Berkeley National Laboratory, Berkeley, CA 94720, USA

${ }^{\mathrm{c}}$ On Leave from Henan Normal University, Henan Provence, China

${ }^{\mathrm{d}}$ Present Address: Material Science and Engineering Department, Stanford University, Stanford, 94305, USA

${ }^{\mathrm{z}}$ Corresponding Author:

Gao Liu

Lawrence Berkeley National Laboratory

1 Cyclotron Rd., MS 70R108B

Berkeley, CA 94720

Office Phone: (510) 486-7207

Office Fax: (510) 486-7303

E-mail: Gliu@lbl.gov 


\begin{abstract}
Fundamental electrochemical methods were applied to study the effect of the acetylene black (AB) and the polyvinylidene difluoride (PVDF) polymer binder on the performance of high-power designed rechargeable lithium ion cells. A systematic study of the $\mathrm{AB} / \mathrm{PVDF}$ long-range electronic conductivity at different weight ratios is performed using four-probe direct current tests and the results reported. There is a wide range of $\mathrm{AB} / \mathrm{PVDF}$ ratios that satisfy the long-range electronic conductivity requirement of the lithium-ion cathode electrode; however, a significant cell power performance improvement is observed at small $\mathrm{AB} / \mathrm{PVDF}$ composition ratios that are far from the long-range conductivity optimum of 1 to 1.25 . Electrochemical impedance spectroscopy (EIS) tests indicate that the interfacial impedance decreases significantly with increase in binder content. The hybrid power pulse characterization results agree with the EIS tests and also show improvement for cells with a high PVDF content. The AB to PVDF composition plays a significant role in the interfacial resistance. We believe the higher binder contents lead to a more cohesive conductive carbon particle network that results in better overall all local electronic conductivity on the active material surface and hence reduced charge transfer impedance.
\end{abstract}

\title{
Key Words
}

Lithium-Ion Battery; Electrode Design; Polymer Composite. 


\section{Introduction}

Lithium-ion rechargeable batteries are a prime candidate for electric vehicle (EV) and hybrid electric vehicle (HEV) applications due to their high energy density and light weight. These applications, especially HEV, require low internal resistance for superb high-rate charge and discharge performance. The lithium-ion cell electrode is composed of active materials, conductive additives and a polymer binder to combine the particles into an integrated electrode system. The cathode active material is made from metal oxide materials which have very low intrinsic conductivity ranging from $10^{-3} \mathrm{~S} / \mathrm{cm}$ for $\mathrm{LiCoO}_{2}$ to $10^{-9} \mathrm{~S} / \mathrm{cm}$ for $\mathrm{LiFePO}_{4}$ at ambient condition. ${ }^{1-4}$ The active material primary particles are sintered into micron-size particles and mixed with highly conductive carbon additives to improve the particle conductivity. In this study, $\mathrm{LiNi}_{0.8} \mathrm{Co}_{0.15} \mathrm{Al}_{0.05} \mathrm{O}_{2}$ is used as active material; acetylene black ( $\mathrm{AB})$ is used as conductive additive; and polyvinylidene difluoride (PVDF) is used as polymer binder. The focus here is the optimization of the composition of the porous composite electrodes to improve the lithium-ion cell performance.

A unique approach is taken to study the lithium-ion battery cathode electrode as a polymer composite. A simple cathode is a three-component composite including a polymer binder and two discreet sized particles: the nano-size $\mathrm{AB}$ and the micro-size $\mathrm{LiNi}_{0.8} \mathrm{Co}_{0.15} \mathrm{Al}_{0.05} \mathrm{O}_{2}$. The specific surface area of the $\mathrm{AB}$ is at least ten times larger than that of the $\mathrm{LiNi}_{0.8} \mathrm{Co}_{0.15} \mathrm{Al}_{0.05} \mathrm{O}_{2}$ material. In a polymer composite system, the surface area dominants the mixing process such that most of the polymer binder in a composite will associate with the smaller size conductive additive, even when the $A B$ is far from being the weight dominant component. ${ }^{5-7}$ In this respect, we view the electrode system as 
a $\mathrm{LiNi}_{0.8} \mathrm{Co}_{0.15} \mathrm{Al}_{0.05} \mathrm{O}_{2}$ cathode material being bond together by an $\mathrm{AB} / \mathrm{PVDF}$ composite. The electronic properties of the AB/PVDF composites naturally affect the performance of the electrode. ${ }^{8}$

In this report, a set of experiments were designed to evaluate the contribution of the long-range electronic conductivity of $\mathrm{AB} / \mathrm{PVDF}$ composites to the overall electrode performance. The long range electronic conductivities of the AB/PVDF composites and the $\mathrm{AB} / \mathrm{PVDF} /$ active material composites were measured via a four-point probe directcurrent (DC) method. ${ }^{9}$ The composite films were cast on glass for the four-point probe DC measurements. Lithium-ion cells of very similar capacity and configuration but with various the $\mathrm{AB} / \mathrm{PVDF}$ ratios were constructed, and their power performance evaluated with variable rate cycling, hybrid pulse power characterization (HPPC) experiments, and electrochemical impedance spectroscopy (EIS).

Most of the previous work on electrode compositions treats the conductive additive and binder as two independent variables: one present for providing electronic conductivity and the other present to hold the electrode components together. ${ }^{10}$ And although $\mathrm{AB}$ does provide electronic conductivity in the cathode electrode, long-range electron pathways cannot be formed without the participation of the binders. Therefore $\mathrm{AB}$ and $\mathrm{PVDF}$ are the integrated parts of the electrode rather than two independent components. ${ }^{11-15}$ We report the electronic properties of the AB/PVDF composites and their effects to the electrode performance. 


\section{Experimental}

\section{$\underline{\text { Materials }}$}

Battery grade $\mathrm{AB}$ with an average particle size of $40 \mathrm{~nm}$ and a material density of $1.95 \mathrm{~g} / \mathrm{cm}^{3}$ was acquired from Denka Singapore Private Limited. PVDF \#1100 binder with a material density of $1.78 \mathrm{~g} / \mathrm{cm}$ was supplied by Kureha, Japan. Anhydrous Nmethylpyrrolidinone (NMP) was purchased from Aldrich Chemical Company. The AB/PVDF mixtures were made by dissolving $5 \mathrm{~g}$ of PVDF in $95 \mathrm{~g}$ of anhydrous NMP. A given amount of $\mathrm{AB}$ was dispersed in the PVDF polymer solution to meet the desired ratio. To ensure the thorough mixing of the $\mathrm{AB}$ nanoparticles into the polymer solution, sonification was used. A Branson 450 sonicator equipped with a solid horn was used. The sonication power was set at $70 \%$. A continuous sequence of $10 \mathrm{~s}$ pulses followed by a $30 \mathrm{~s}$ rests was used. The sonic dispersion process took about 30 minutes. The slurry properties for all $\mathrm{AB} / \mathrm{PVDF}$ in NMP were constant after 20 minutes of sonification. Slurries with active cathode material were made by adding the targeted amount of $\mathrm{LiNi}_{0.8} \mathrm{Co}_{0.15} \mathrm{Al}_{0.05} \mathrm{O}_{2}$ active material to into premixed $\mathrm{AB} / \mathrm{PVDF} / \mathrm{NMP}$ slurry. The cathode mixture was homogenized using Polytron PT10-3S Homogenizer at 3000 RPM for 15 minutes until viscous slurry is acquired. $\mathrm{LiNi}_{0.8} \mathrm{Co}_{0.15} \mathrm{Al}_{0.05} \mathrm{O}_{2}$, with a mean particle size of $10 \mu \mathrm{m}$ and lattice density of $4.73 \mathrm{~g} / \mathrm{cm} 3$, was a gift from Toda, Japan. The manufacture suggested specific capacity is $173 \mathrm{mAh} / \mathrm{g}$ when cycled between $3 \mathrm{~V}$ and 4.1 V. 


\section{$\underline{\text { Film and Electrode Casting }}$}

In order to understand the conductive behavior of the AB/PVDF composite system, different weight ratios of $\mathrm{AB}$ are dispersed in PVDF-NMP solutions and cast into thin films. The film compositions extend from 1:10 to 1:1 AB/PVDF weigh ratios. The films show cracks beyond the $\mathrm{AB} / \mathrm{PVDF}$ ratio of $1: 1$, which would indicate that mixtures with less than this fraction of binder may not effectively maintain coherent, long-range conductivity in an electrode. $\mathrm{AB} / \mathrm{PVDF}$ ratios greater than 1:1 will also likely to result in mechanically weak composites. $\mathrm{LiNi}_{0.8} \mathrm{Co}_{0.15} \mathrm{Al}_{0.05} \mathrm{O}_{2}$ active material was used with the $\mathrm{AB} / \mathrm{PVDF}$ to fabricate electrodes. The $\mathrm{AB}$ content was fixed at $4 \%$ by weight in three electrode compositions, but the amount of PVDF binder was varied to achieve AB/PVDF weight ratios of $1: 2,1: 1.25$ and $1: 1$.

Both $\mathrm{AB} / \mathrm{PVDF}$ and $\mathrm{AB} / \mathrm{PVDF} / \mathrm{LiNi}_{0.8} \mathrm{Co}_{0.15} \mathrm{Al}_{0.05} \mathrm{O}_{2}$ films for the four-point probe DC tests were cast on to glass surfaces with a doctor blade. Cathode laminates $\left(\mathrm{AB} / \mathrm{PVDF} / \mathrm{LiNi}_{0.8} \mathrm{Co}_{0.15} \mathrm{Al}_{0.05} \mathrm{O}_{2}\right)$ for coin-cell testing was cast on $30 \mu \mathrm{m}$ thick battery grade $\mathrm{Al}$ sheet using a Mitutoyo doctor blade and a Yoshimitsu Seiki vacuum drawdown coater. The films and laminates were first dried under IR lamps for an hour until most of the NMP was evaporated and they appeared dried. The films and laminates were further dried at $120^{\circ} \mathrm{C}$, under $10^{-2}$ torr pressure for 24 hours. The film and laminate thickness was measured with a Mitutoyo micrometer with an accuracy of $1 \mu \mathrm{m}$. The typical thickness of the AB/PVDF film is around $20 \mu \mathrm{m}$ with a density of around $1.2 \mathrm{~g} / \mathrm{cm}^{3}$. The typical thickness of the $\mathrm{AB} / \mathrm{PVDF} / \mathrm{LiNi}_{0.8} \mathrm{Co}_{0.15} \mathrm{Al}_{0.05} \mathrm{O}_{2}$ film is approximately $50 \mu \mathrm{m}$ with an initial porosity around $52 \%$. The electrodes were compressed to $35 \%$ porosity before coin

cell assembly using a rolling mill with a continuously adjustable gap from International 
Rolling Mill. The gap between the rollers was set at the targeted thickness. The electrode laminate was fed through the gap to compress the electrode to the thickness accounted for $35 \%$ overall porosity.

\section{Film Imaging}

The morphology of $\mathrm{AB} / \mathrm{PVDF}$ films at different ratios were imaged by scanning electron microscopy (SEM) and a transmission electron microscopy (TEM). A JEOL FESEM set at $5 \mathrm{kV}$ was used to image the surface of the films. The TEM was used to image internal sections of the films. A RMC Boeckeler PR XL ultramicrotome was used to prepare $50 \mathrm{~nm}$ thin sections for the TEM. Samples were embedded in low viscosity Spurr's epoxy for added stability when sectioning. Films were also cryomicrotomed at $100^{\circ} \mathrm{C}$ using a cryogenic attachment and a glass knife. After the samples were sectioned they were then carbon coated to help dissipate charge. Imagine was done using a JEOL $200 \mathrm{CX}$ microscope operating at $200 \mathrm{kV}$. All imaging work was performed at the National Center for Electron Microscopy at Lawrence Berkeley National Laboratory.

\section{Four-Point Probe DC Testing}

The DC conductivity measurement was performed using a custom-built equaldistance linear four-point probe apparatus with a Solartron1286 Electrochemical Interface and a CorrWare software package. A direct current is applied between the two outer probes; the voltage is registered between the two inner probes. The probes are spring loaded to ensure intimate contact between and probes and the films. The conductivity of each film was measured four times at the different locations on the film with the standard 
deviations shown as error bars. Electrolyte solvent was made by mixing 1:1 weight ratio of ethylene carbonate (EC) and diethylene carbonate (DEC) for the four-probe DC test. No salt was added to the electrolyte solvent to prevent ion interference with the measurements. The film was submerged in the electrolyte solvent and the conductivity measurements repeated, intermittently, until it constant value was recorded. The conductivities of the $\mathrm{AB} / \mathrm{PVDF}$ and $\mathrm{AB} / \mathrm{PVDF} / / \mathrm{LiNi}_{0.8} \mathrm{Co}_{0.15} \mathrm{Al}_{0.05} \mathrm{O}_{2}$ films on glass substrate were measured using the four-point probe DC method. ${ }^{9}$ The dry film conductivities were measured after the films were dried in a vacuum oven overnight at $120^{\circ} \mathrm{C}$. Afterwards, the films were wetted with electrolyte solvent and their conductivities were measured again.

\section{$\underline{\text { Coin Cell Fabrication and Testing }}$}

Coin cell assembly was prepared in standard 2325 coin cell hardware with $\mathrm{LiNi}_{0.8} \mathrm{Co}_{0.15} \mathrm{Al} \quad{ }_{0.05} \mathrm{O}_{2}$ as the active cathode material. The cathode laminates were prepared with different $\mathrm{AB} / \mathrm{PVDF}$ contents. A $1.26 \mathrm{~cm}$ diameter disk was punched out from the cathode laminate for use in the coin cell assembly. Both lithium metal and MCMB10-28 graphite were used as counter electrodes. The counter electrodes are 1.47 $\mathrm{cm}$ diameter disks, which are larger than the cathode to prevent lithium deposition at high charge rate. The cathode electrode was placed in the center of the outer shell of the coin cell assembly and 2 drops of $1 \mathrm{M} \mathrm{LiPF}_{6}$ in EC:DEC (1:1 weight ratio) electrolyte added to fill the electrode. A $2 \mathrm{~cm}$ diameter of Celgard 2400 porous polyethylene separator was place on top of the cathode electrode. A few drops the electrolyte were added to the separator. The counter electrode was placed on the top of the separator. Special care was taken to align the counter electrode symmetrically above the cathode. A stainless steel 
spacer and a Belleville spring were placed on top of the counter electrode. Plastic grommet was placed on top of the outer edge of the electrode assembly and crimped closed with a custom-build hydraulic crimping machine manufactured by National Research Council of Canada. The entire cell fabrication procedure was done in an Argon filled glove box at oxygen level below $0.1 \mathrm{ppm}$ and dew point below $-80^{\circ} \mathrm{C}$.

The coin cell performance was evaluated in a thermal chamber at $30^{\circ} \mathrm{C}$ with a Maccor Battery Test System. The electrode rate performance was characterized against lithium counter electrode and MCMB10-28 counter electrode coin cells. The cycling voltage limits were set at $4.1 \mathrm{~V}$ at the top of charge and $3.0 \mathrm{~V}$ at the bottom of charge. The coin cells made with MCMB10-28 graphite were first formed by going through 2 cycles at $\mathrm{C} / 25$ at $30^{\circ} \mathrm{C}$. The EIS tests were performed at $40 \%$ depth of discharge (DOD) at frequencies between $10^{5} \mathrm{~Hz}$ to $0.01 \mathrm{~Hz}$ using a Solartron 1260 Impedance/Gain-phase Analyzer and Z-plot software package. HPPC tests were performed only on the MCMBbased coin cells following the established procedures. ${ }^{16}$

\section{Results and discussion}

The DC Conductivities of the AB/PVDF and AB/PVDF/ $\mathrm{LiNi}_{0.8} \underline{\mathrm{Co}}_{0.15} \underline{\mathrm{Al}_{0.05}} \underline{\mathrm{O}}_{2}$ cast films.

Figure 1 is the conductivity plot of the AB/PVDF film at different compositions. The conductivity increases with increasing $\mathrm{AB}$ content and peaks at 1:1.25 $\mathrm{AB}$ to PVDF. ${ }^{17}$ An increase in $\mathrm{AB}$ content beyond 1:1.25 resulted in cracked films and a significant decrease in the conductivity. This is due to the lack of PVDF binder needed to hold all the carbon particles together. When the composites are in contact with excess 
electrolyte, conductivities of the wet films are only a third as high as the conductivity of the dry films. The AB particles are separated with a thin layer of PVDF binder. ${ }^{18}$ It is well known that the PVDF swells in the presence of electrolyte. ${ }^{19}$ The distance between the conductive $\mathrm{AB}$ particles is increased when the PVDF layer between the particles swells, resulting in the drop of electronic conductivity. The wetted condition is more representative of the electronic conductivity one might expect in a functioning cell. However, the figure shows that even at $\mathrm{AB} / \mathrm{PVDF}$ ratio of $1: 5$, the composite conductivity is still greater than $0.1 \mathrm{~S} / \mathrm{cm}$ which is still far greater than the electronic conductivity of the active material and of the electrolyte, which has conductivity on the order of $10^{-2}-10^{-3} \mathrm{~S} / \mathrm{cm}^{20-22}$

Among the compositions shown in Figure 1, 1:2, 1:1.25, and 1:1 AB/PVDF were selected for further testing with active material. 1:1.25 gave the best electronic conductivity among all the AB/PVDF compositions; $1: 2$ and $1: 1$ have similar conductivity but straddle the optimum. In the three electrode compositions tested, the conductive additive $\mathrm{AB}$ was fixed at $4 \%$ by weight and the PVDF and active material contents varied in order to achieve the desired AB/PVDF ratios. Although the conductive additive is constant in all three compositions, the long-range electronic conductivity of the composite electrodes changed, as shown in Figure 2. This trend is in agreement with the conductivity behavior of the AB/PVDF thin films (Figure 1). In a none calendared electrode film, $52 \%$ of volume is void space, $48 \%$ is occupied by $\mathrm{AB} / \mathrm{PVDF} / \mathrm{LiNi}_{0.8} \mathrm{Co}_{0.15} \mathrm{Al}_{0.05} \mathrm{O}_{2}$ as reported in the experimental section. Considering the material densities and the PVDF and $\mathrm{LiNi}_{0.8} \mathrm{Co}_{0.15} \mathrm{Al}_{0.05} \mathrm{O}_{2}$ contents as shown in Table 1, the volume ratio of the $\mathrm{AB} / \mathrm{PVDF}$ is only around $10 \%$ of the total volume of the electrode as labeled in Figure 2. This 10\% volume ratio of the AB/PVDF of the electrode agrees 
well with the $90 \%$ drop of long range electronic conductivity of the composite films. The $\mathrm{AB} / \mathrm{PVDF}$ composite is the major component to allow for conductivity of the electrode. A similar result of electronic conductivity drop is seen for composite films with electrolyte added. Despite the additional drop in conductivity of the composite electrodes, all three electrode compositions still maintain significantly higher electronic conductivities than the electronic conductivity of either $\mathrm{LiNi}_{0.8} \mathrm{Co}_{0.15} \mathrm{Al}{ }_{0.05} \mathrm{O}_{2}$ or the conductivity of the electrolyte. ${ }^{20-22}$

\section{Morphologies of the Composites}

SEM was used to correlate the AB/PVDF films' surface morphology to their conductivity as shown in Figure 3. At low AB loading (Figure 3 A), a continuous polymer phase was clearly visible (white arrows) with aggregates of $A B$ embedded in it. With increasing $\mathrm{AB}$ concentration (Figure $3 \mathrm{~B}, \mathrm{C}$ ), $\mathrm{AB}$ becomes more abundant on the surface with the retreat of the polymer phase. Although the $1: 1$ ratio of $\mathrm{AB} / \mathrm{PVDF}$ appears uniform under visual examination, low magnification SEM images (Figure $3 \mathrm{C}$, in-set) show extended micro cracks in the film. This loss of mechanical integrity is attributed to the decrease of conductivity with increasing $\mathrm{AB}$ content beyond the optimum electronic conductivity level at 1:1.25 AB/PVDF ratio.

In a working composite electrode, electrons are transported mostly through the $\mathrm{AB} / \mathrm{PVDF}$ of the composite system, and, therefore, the conductivity of this pathway is critical to the electrode performance. We therefore felt the need to study the morphology of this pathway more closely. AB/PVDF of 1:2, 1:1.25, and 1:1 ratios were studied. These three samples covered the binder rich, optimum conductivity, and $A B$ rich 
composition. As shown in the TEM images in Figure 4, the acetylene black is not uniformly distributed in the binder. There are distinct phases that are either binder rich or $\mathrm{AB}$ aggregate rich. At higher binder contents, the $\mathrm{AB}$ forms extended 3-dimensional networks to provide long range conductivity while free polymer forms another phase within the $\mathrm{AB}$ network. At 1:2 composition, TEM image (Figure 4, A) shows that pure PVDF phases exist that do not contribute to the composite long-rang conductivity, and that extended $\mathrm{AB}$ agglomerate phase as current path. There are very few visible regions of free polymer phases observable under TEM at a 1:1.25 AB/PVDF ratio and greater, (Figure 4, B, C) due to the fact that the PVDF is mostly associated with AB particles rather than form its own phases. ${ }^{23}$ As a reminder, electronic conductivity peaks at 1:1.25 and decreases at 1:1 $\mathrm{AB} / \mathrm{PVDF}$ ratio. There appears to be a minimum requirement of polymer at 1:1.25 to tightly bind the $\mathrm{AB}$ particles together. The disappearing of free polymer phases with increasing $\mathrm{AB}$ ratio is due to the strong interaction between the polymer and $\mathrm{AB}$ particle surface. The polymer molecules can be adsorbed onto the $\mathrm{AB}$ surface either chemically or physically. With increasing $A B$ content, the free polymer regions transform into mostly surface absorbed layers around the AB particles. ${ }^{5}$

\section{Electrochemistry Testing}

Cathode laminates of varying $\mathrm{AB} / \mathrm{PVDF}$ weight ratios of $1: 2,1: 1.25$, and $1: 1$ on aluminum substrates were tested in coin cells against lithium foil and MCMB counter electrodes. The AB content in all of the cells was held at 4\%. The detailed cell compositions and configurations are listed in Table 1. The porosity of the three electrodes was held constant at $35 \%$ in order to minimize the configuration effects of the cell performance. The capacity and thickness of the three electrodes are controlled at 
$10 \%$ standard deviation in order to minimize the configuration effects to the cell performance. ${ }^{24}$ However it should be noted that a small variation of either parameters can't be entirely eliminated because active material content also changes a few percents due to the change of PVDF. Although only 4\% change of PVDF content, this brings a $50 \%$ change in the $\mathrm{AB} / \mathrm{PVDF}$ ratios among three electrodes. All coin cell capacities agree well with the literature suggested $\mathrm{LiNi}_{0.8} \mathrm{Co}_{0.15} \mathrm{Al}_{0.05} \mathrm{O}_{2}$ material capacity of 173 $\mathrm{mAh} / \mathrm{g}$ during $\mathrm{C} / 10$ charge and discharge tests between $3 \mathrm{~V}$ and $4.1 \mathrm{~V}$ as shown in Table 1. ${ }^{25}$ Figure 5 shows the rate performance of three lithium counter-electrode cells. These cells are charged at $\mathrm{C} / 10$ rate and discharged at different rates. The discharge capacities of the cells are normalized as the measured discharge capacities at variable C-rate divided by the corresponding cell capacity as shown in Table 1 . All three cells perform similarly at low to medium rate. However the performances diverge at high rates. The electrode with the optimum electronic conductivity $(\mathrm{AB} / \mathrm{PVDF}=1: 1.25)$ is not the best performing cell at high rates. The cell with the highest binder content $(\mathrm{AB} / \mathrm{PVDF}=1: 2)$, gives the best capacity retention at high rates. The cell with lowest binder content $(\mathrm{AB} / \mathrm{PVDF}=$ $1: 1)$ performs the worst.

In order to better interpret these results, EIS was performed on all three cells at $40 \%$ DOD, as shown in Figure 6. The major difference in the impedance data between the three cells is the interfacial resistance represented by the squashed semicircle in the high frequency region of the spectrum. The width of the semicircle increases with decreasing binder content. Similar results were observed with coin cells made containing MCMB1028 as the counter electrode, as shown in Figure 7. The width of the semicircles in Figures 6 and 7 each contain contributions from the interfacial impedance from the counter electrodes, with a smaller contribution coming from the graphite than that of the lithium. 
Separate experiments with reference electrodes (not shown) performed cells with lithium foil indicate that the lithium contributes very little to the overall cell impedance. The increase in impedance with removal of binder is thus a major contributor to the cell impedance and lead to a loss of capacity at high rates. HPPC tests were performed on three MCMB-based counter electrode coin cells, with the results plotted in Figure 8. The area specific impedance (ASI) data is in very good agreement with the EIS test, as the $\mathrm{AB} / \mathrm{PVDF}=1: 2$ composition gave the lowest ASI of the three cells across the entire DOD range, followed by 1:1.25, and then 1:1.

Figure 9 is a schematic of the cathode particle and its environment in the working electrodes with lithium-ion transport and electron movement pathways identified. The open space is occupied by the electrolyte where lithium-ions can move in and out of the active materials, while the black is the $\mathrm{AB} / \mathrm{PVDB}$ electronic contact to the active materials. The schematic is not drawn to scale but to demonstrate the possible contributions of the spices during electrochemical process. All three electrodes are designed to minimize the configuration contribution to the impedance variation. Since the porosities are controlled at $35 \%$, the electrolyte mass-transfer rate within the electrode is very similar among all 3 compositions (Figure 9, A). The close-matching of the capacities ensures very similar active material surface areas among all three electrodes. There are two major changing factors among the three electrodes. The long range matrix electronic conductivities of the electrodes are in the order of 1:1.25>1:1>1:2. Should the matrix conductivity be the limiting factor (Figure 9, B) for all 3 electrodes, the power performance starting from the best would be in the order of 1:1.25>1:1>1:2. PVDF is viewed as a nonconductive material in the electrode composition. Increasing its amount could exert a lithium-ion blocking effect both in the electrolyte and at the active material 
interface, which might slow down the lithium-ion transfer in the electrolyte or at the interface. (Figure 9, A, C) Should this be the scenario, the power performance starting from the best would be $1: 1>1: 1.25>1: 2$. Neither of the above hypotheses is correct, so the only possibility is the variation of the electronic conductivity (Figure 9, D) between the active material particles and the AB/PVDF composite, which can affect the lithium-ion transfer at the interface. Figure 10 is schematic pictures of the active material particle in combination with the TEM image of the AB/PVDF composites. This schematics is not drawn to scale but to illustrate the possible mechanism of the critical role of the binder in designing cell for power performance. The existing of pure polymer phase in 1:2 (Figure 10, A) may serve a critical function to provide and maintain better mechanical contact between the active material and $\mathrm{AB}$ conductive pathways rather than slowing down lithium-ion transfer at the interface. Intimate contact between the $\mathrm{AB}$ and the active materials allows effective local electronic charge injection therefore facilitate lithium-ion transfer at the interface. At low binder loading, the $\mathrm{AB}$ tends to move away from the active material to form agglomerate by itself due to the flocculation phenomenon. ${ }^{26,27}$ This AB micro-scale structures do not affect the long range conductivity but significantly alters the interfacial impedance.

\section{Conclusions}

The long-range electronic conductivity in a composite electrode is almost exclusively provided by the $\mathrm{AB} / \mathrm{PVDF}$ matrix. A wide range of compositions of $\mathrm{AB} / \mathrm{PVDF}$ ratios tend to satisfy the long-range electronic conductivity requirement of lithium-ion cathodes. This long-range electronic conductivity does not play an important factor for high rate performance as much as the interfacial resistance does. Our research indicates that the 
ratio of carbon conductive additive to binder ratio is a critical parameter in optimizing the interfacial resistance, with higher binder contents being more beneficial. Thus, the PVDF binders play a significant role in that it not only helps maintain electrode integrity, it also provides intimate contact between the conductive additive and the active material particles resulting in high, localized electronic conductivity at the active material interface thus decreasing interfacial impedance.

\section{Acknowledgments}

This research was funded by the Assistant Secretary for Energy Efficiency and Renewable Energy, Office of FreedomCAR and Vehicle Technologies of the U.S. Department of Energy under contract no. DE-AC03-76SF00098. 


\section{References}

1. S. Y. Chung, J. T. Bloking, and Y. M. Chiang, Nat. Mater. 1 (2), 123 (2002).

2. A. K. Padhi, K. S. Nanjundaswamy, and J. B. Goodenough, J. Electrochem. Soc. 144 (4), 1188 (1997).

3. H. Tukamoto and A. R. West, J. Electrochem. Soc. 144 (9), 3164 (1997).

4. J. Wolfenstine, J. Power Sources 129 (2), 324 (2004).

5. $\quad$ E. M. Dannenberg, Rubber Chem. Technol. 59 (3), 512 (1986).

6. J. C. Kenny, V. J. McBrierty, Z. Rigbi et al., Macromolecules 24 (2), 436 (1991).

7. A. I. Medalia, J. Colloid Interface Sci. 32 (1), 115 (1970).

8. K. Miyasaka, K. Watanabe, E. Jojima et al., J. Mater. Sci. 17 (6), 1610 (1982).

9. C. W. Wang, A. M. Sastry, K. A. Striebel et al., J. Electrochem. Soc. 152 (5), A1001 (2005).

10. L. Fransson, T. Eriksson, K. Edstrom et al., J. Power Sources 101 (1), 1 (2001).

11. Z. H. Chen, L. Christensen, and J. R. Dahn, J. Electrochem. Soc. 150 (8), A1073 (2003).

12. D. Guy, B. Lestriez, R. Bouchet et al., Electrochem. Solid State Lett. 8 (1), A17 (2005).

13. D. Guy, B. Lestriez, R. Bouchet et al., J. Electrochem. Soc. 153 (4), A679 (2006).

14. K. Zaghib, J. Shim, A. Guerfi et al., Electrochem. Solid State Lett. 8 (4), A207 (2005).

15. Y. H. Chen, C. W. Wang, G. Liu et al., presented at the The 211th Electrochemical Society Meeting, Chicago, IL, 2007.

16. T. Q. Duong, J. Power Sources 89 (2), 244 (2000).

17. Y. B. Yi and A. M. Sastry, Phys. Rev. E 66 (6) (2002). 
18. F. Carmona, Ann. Chim.-Sci. Mat. 13 (6), 395 (1988).

19. Z. H. Chen, L. Christensen, and J. R. Dahn, J. Appl. Polym. Sci. 91 (5), 2958 (2004).

20. K. Xu, S. S. Zhang, and T. R. Jow, Electrochem. Solid State Lett. 8 (7), A365 (2005).

21. G. M. Ehrlich, Lithium-ion Batteries, 3rd ed ed. (McGraw-Hill: New York, 2002, 2002).

22. R. Kostecki and F. McLarnon, Electrochem. Solid State Lett. 7 (10), A380 (2004).

23. C. M. Blow, Polymer 14 (7), 309 (1973).

24. D. Y. W. Yu, K. Donoue, T. Inoue et al., J. Electrochem. Soc. 153 (5), A835 (2006).

25. R. B. Wright, J. P. Christophersen, C. G. Motloch et al., J. Power Sources 119, 865 (2003).

26. B. W. Derryaguin and L. D. Landau, Act. Physchem. SSSR 14, 375 (1941).

27. E. J. W. Verwey and J. Th. G. Overbeek, Theory of Stability of Lipophobic Colloids. (Elseview, Amsterdam, 1948). 


\section{Figure Captions}

Figure 1. Long range electronic conductivity of $\mathrm{AB} / \mathrm{PVDF}$ composite films characterized by four-point probe DC test at different $\mathrm{AB}$ to PVDF ratios.

Figure 2. Long range electronic conductivity of three $\mathrm{LiNi}_{0.8} \mathrm{Co}_{0.15} \mathrm{Al}_{0.05} \mathrm{O}_{2}$ cathodes with constant $4 \% \mathrm{AB}$ by weight. The Vol. labels indicate the volume ratios of the AB/PVDF composite to the overall electrode volume.

Figure 3. SEM surface images of the AB/PVDF composites. (A) AB:PVDF $=1: 2$. Free polymer is seen on the surface of $\mathrm{AB}$ as pointed out by the arrows. (B) AB:PVDF = 1:1.25. (C) AB:PVDF $=1: 1$

Figure 4. TEM bulk morphology of AB/PVDF composites. (A) AB:PVDF = 1:2. Solid lines indicate the $\mathrm{AB}$ aggregate phases and current paths. Dotted line enclosures indicate free PVDF phases. (B) AB:PVDF $=1: 1.25$. (C) AB:PVDF $=1: 1$. Higher $\mathrm{AB}$ concentration composites lack the free PVDF phases.

Figure 5. Variable rate performance of the lithium counter electrode coin cells made from cathode electrode with different AB/PVDF ratios.

Figure 6. EIS of the lithium counter electrode coin cells at 40\% DOD.

Figure 7. EIS of the MCMB10-28 counter electrode coin cells at 40\% DOD. 
Figure 8. HPPC test results of the MCMB10-28 counter electrode coin cells.

Figure 9. Schematic of the micro-scale cathode local environment. (A) lithium-ion mass transfer in the electrolyte. (B) Electron pathway in the AB/PVDF composite. (C) Lithium-ion transfer at the electrolyte-active material interface. (D) Electron transfer at

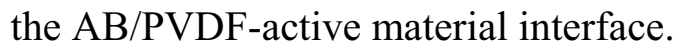

Figure 10. Schematics of the interactions between active material particle and the AB/PVDF composites. (A) Free polymer phases provide adhesion to pull the $A B$ conductive phases toward the active material particles as indicated by the white arrows. (B) Lack of free polymer phase in higher $\mathrm{AB}$ concentration composite results in $\mathrm{AB}$ conductive particles move away form the active material due to $A B$ particle selfattractions. 


\section{Table Caption}

Table 1. The compositions and configurations of three $\mathrm{LiNi}_{0.8} \mathrm{Co}_{0.15} \mathrm{Al}_{0.05} \mathrm{O}_{2}$ cathode electrodes. 


\begin{tabular}{|c|c|c|c|c|c|c|}
\hline$\ddot{ت}$ & $\stackrel{\diamond}{\stackrel{े}{े}}$ & $\stackrel{\circ}{\stackrel{0}{े}}$ & ڤั & $\bar{m}$ & تِّ & ஷें \\
\hline 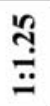 & $\stackrel{\circ}{\circ}$ & i̊ & 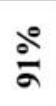 & ले & g్ & ڤે \\
\hline$\stackrel{\stackrel{ }{ت}}{ }$ & 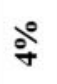 & ஓे & $\stackrel{\infty}{\infty}$ & en & $\stackrel{\infty}{\stackrel{\infty}{\varphi}}$ & 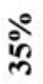 \\
\hline 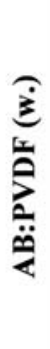 & 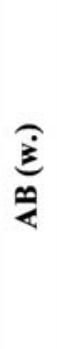 & 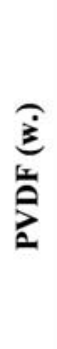 & 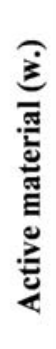 & 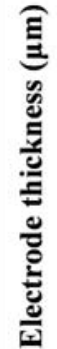 & 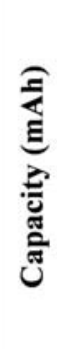 & 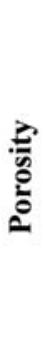 \\
\hline
\end{tabular}




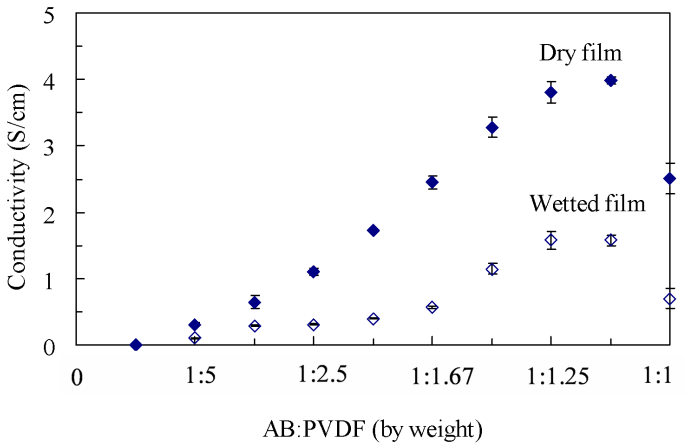




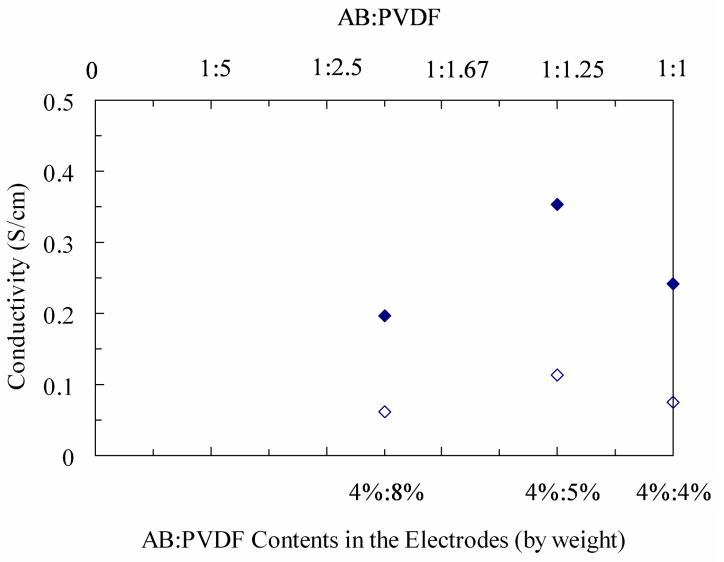




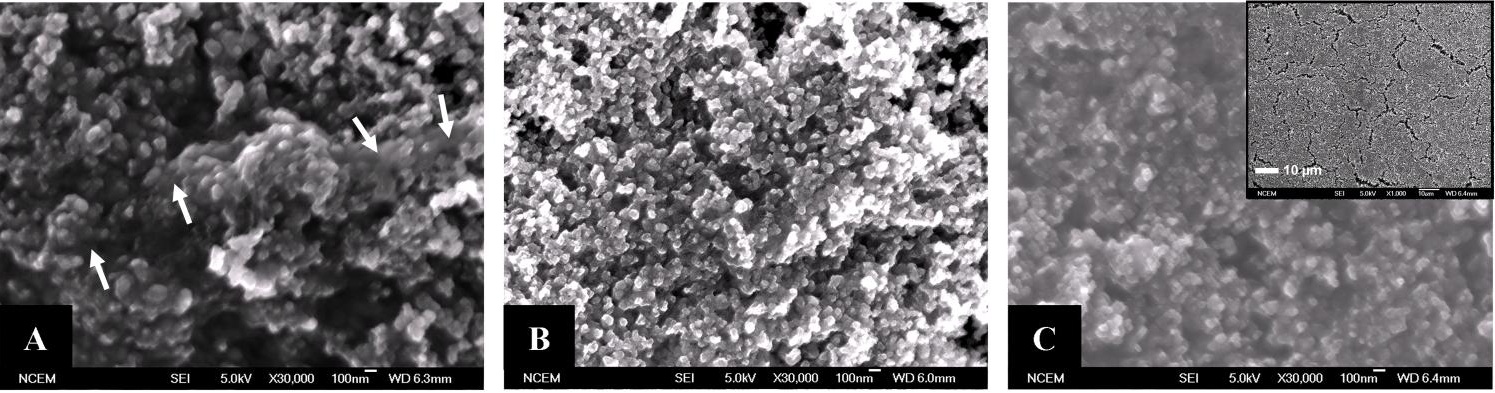




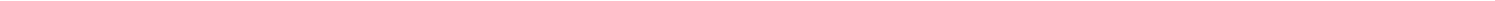




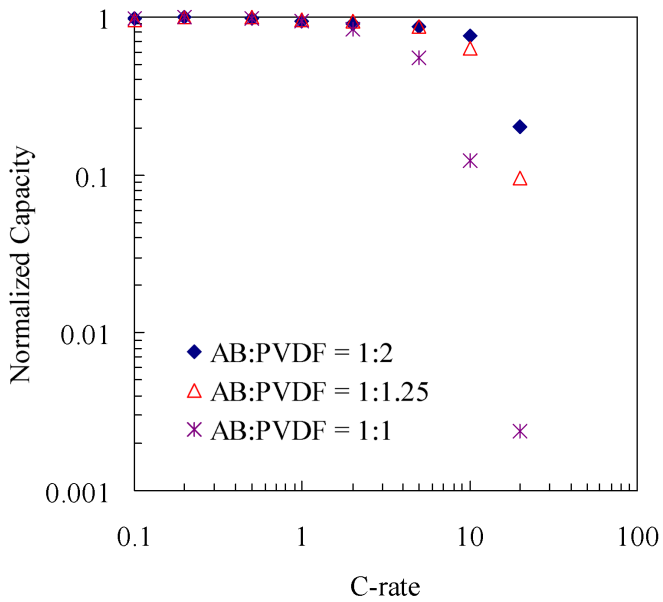




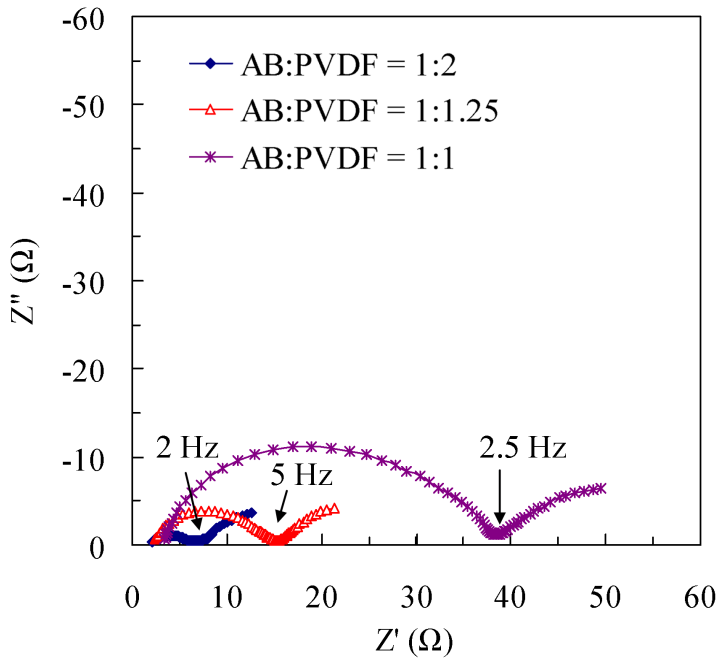




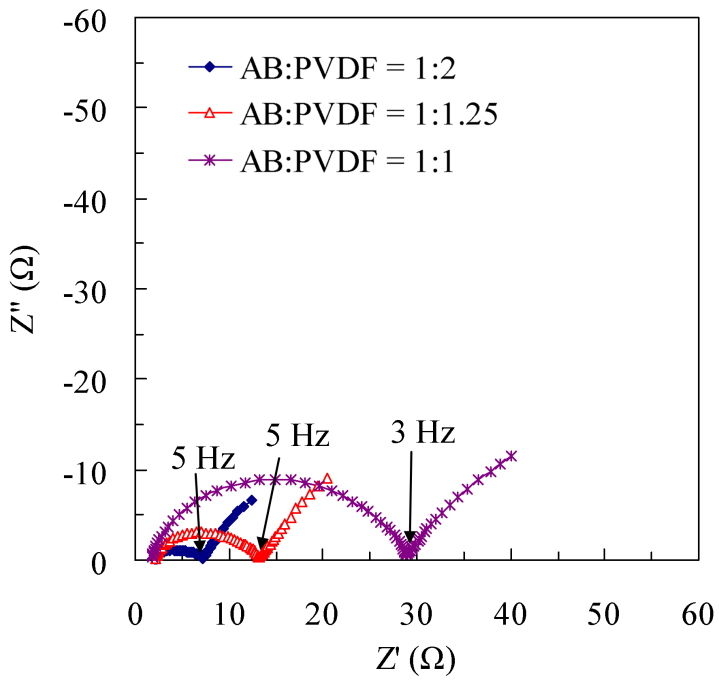




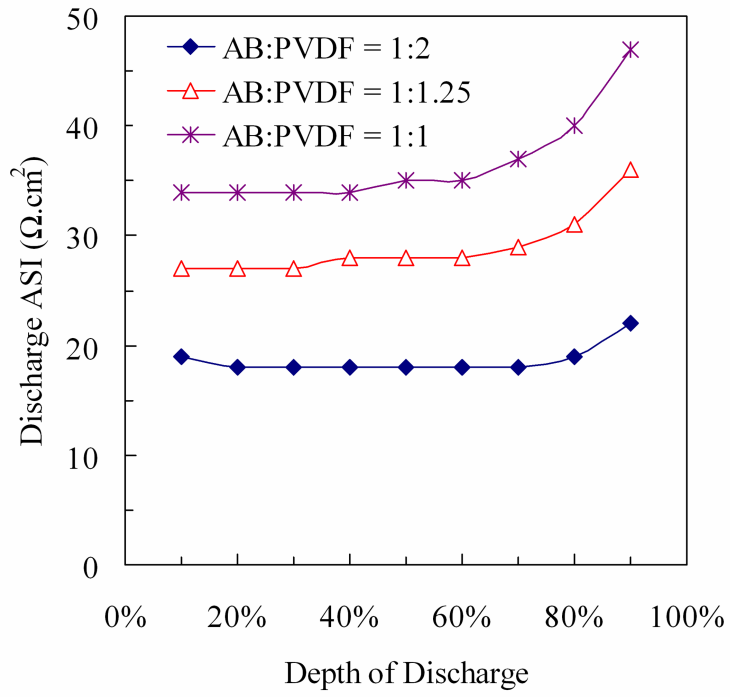




\section{$\mathbf{L i}^{+}$}

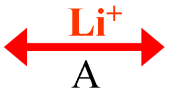

$\mathrm{Li}^{+} \mathrm{C} \mathrm{y}^{\mathrm{x}}$

\section{Electrolyte}

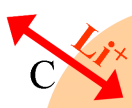
$\mathrm{Li}^{+}$

\section{Active}

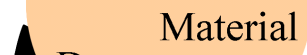

D $\mathrm{B}^{-} \mathrm{AB} / \mathrm{PVDF}$ 

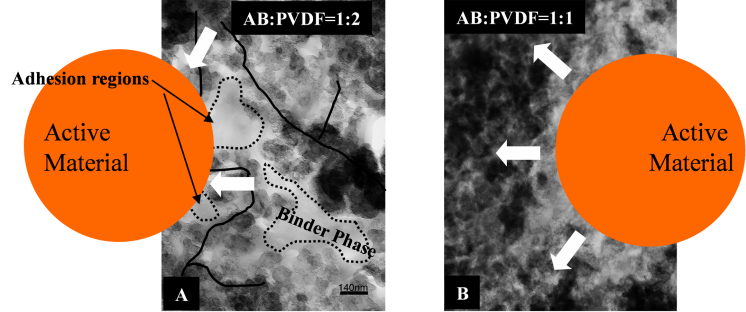